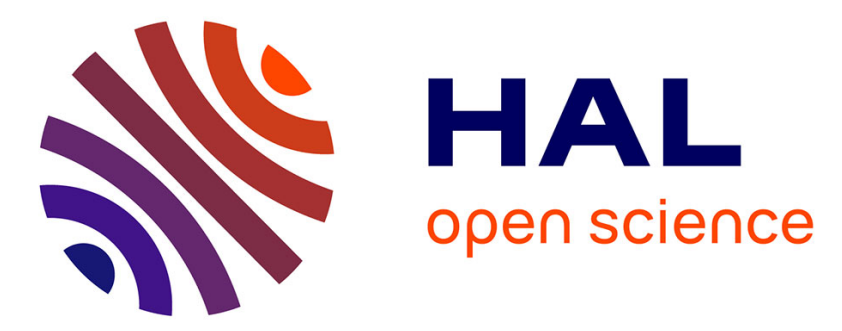

\title{
What are the most important symptoms to assess in hypermobile Ehlers-Danlos syndrome? A questionnaire study based on the Delphi technique
}

Adrien Hakimi, Cyrille Bergoin, Patrick Mucci

\section{To cite this version:}

Adrien Hakimi, Cyrille Bergoin, Patrick Mucci. What are the most important symptoms to assess in hypermobile Ehlers-Danlos syndrome? A questionnaire study based on the Delphi technique. Disability and Rehabilitation, 2021, Disability and Rehabilitation, pp.1-7. 10.1080/09638288.2021.2012839 . hal-03533764

HAL Id: hal-03533764

https://hal.univ-lille.fr/hal-03533764

Submitted on 19 Jan 2022

HAL is a multi-disciplinary open access archive for the deposit and dissemination of scientific research documents, whether they are published or not. The documents may come from teaching and research institutions in France or abroad, or from public or private research centers.
L'archive ouverte pluridisciplinaire HAL, est destinée au dépôt et à la diffusion de documents scientifiques de niveau recherche, publiés ou non, émanant des établissements d'enseignement et de recherche français ou étrangers, des laboratoires publics ou privés. 
This is an Accepted Manuscript of an article published by Taylor \& Francis in Disability and Rehabilitation on 18 December 2021, available online:

https://www.tandfonline.com/doi/full/10.1080/09638288.2021.2012839."

Title: What are the most important symptoms to assess in hypermobile Ehlers-Danlos Syndrome? A questionnaire study based on the Delphi technique.

Authors:

Adrien Hakimi ${ }^{1,2}$,

https://orcid.org/0000-0003-2595-9819.

Cyrille Bergoin ${ }^{2,3 *}$,

https://orcid.org/0000-0001-6581-1056

Patrick Mucci ${ }^{1 *}$,

https://orcid.org/0000-0001-6703-1600

${ }^{1}$ Univ. Lille, Univ. Artois, Univ. Littoral Côte d'Opale, ULR 7369 - URePSSS - Unité de Recherche Pluridisciplinaire Sport Santé Société, F-59000 Lille, France.

${ }^{2}$ Clinique de la Mitterie, Lomme, France.

${ }^{3}$ Cabinet de pneumologie, Tourcoing, France.

* Dr. Cyrille Bergoin and Prof. Patrick Mucci contributed equally to this paper.

\section{Corresponding author:}

Adrien Hakimi

URePSSS, Eurasport, 413, avenue Eugène Avinée, 59120 Loos, France.

adrien.hakimi.etu@univ-lille.fr 


\section{Abstract:}

Purpose: This study aims to determine from questionnaires, submitted to patients with EhlersDanlos Syndromes hypermobile type (hEDS), what symptoms they perceive as having the most impact on their well-being and, according to them, what symptoms should be assessed.

Materials and method: Three rounds of online questionnaires were conducted following the Delphi method. The first round allowed us to obtain the most important symptoms to assess according to the patients. The second and third round aimed at ranking the categories according to their order of importance. Establishment of a consensus was evaluated using a Kendall's coefficient of concordance.

Results: A total of 118 responses was analysed for the first round and 87 for the second and the third round. Ten categories were extracted from the first round. Ranking of the ten categories in the second round did not reach consensus $(\mathrm{W}=0.33, \mathrm{p}<0.001)$ nor did the four most important categories in the third round $(\mathrm{W}=0.43, \mathrm{p}<0.001)$. However three categories stand out from ranking: "pain", "fatigue and sleep disorders" and "musculoskeletal disorders".

Conclusion: These categories seem to be the most important to assess in patients with hEDS, despite the lack of consensus on this ranking.

Keywords: Delphi Technique; Ehlers-Danlos symptoms; Ehlers-Danlos Syndrome; Joint hypermobility; Symptom Assessment 


\section{Introduction}

Ehlers-Danlos Syndromes (EDS) are a group of inherited connective tissue disorders mainly characterized by joint hypermobility, skin hyperextensibility, and tissue fragility [1]. These syndromes present a great clinical and genetic heterogeneity and, since 2017, have been classified in 13 subtypes [1]. The most common is the Ehlers-Danlos syndrome hypermobile type (hEDS) of which the diagnosis remains clinical [1,2].

Several authors have investigated symptoms in EDS through questionnaires or clinical assessments and a wide variety of symptoms have been described, both musculoskeletal and non-musculoskeletal [3-8]. This significant phenotypic variability has led to the use of numerous evaluation tools in EDS research. However, the need for studies with a high level of evidence regarding the management of these patients requires the use of appropriate and common tools in order to make comparison possible [9]. For this reason, it is important to know which symptoms the patients would like to see improved and therefore which ones are the most important to assess.

Most studies focus on the severity or the frequency of these symptoms while few explore the impact of these symptoms on quality of life $[5,6]$. Some Authors have pointed to the lack of studies on the lived experience of these patients [10]. Elements that are most often highlighted in qualitative studies include lack of understanding on the part of health professionals, restrictions in daily life and social stigma [11-13]. To our knowledge, only one study, including teenagers diagnosed with hEDS, has evaluated the relative importance of symptoms [8]. However, this study did not focus on the symptoms that had to be assessed nor on obtaining consensus based on patients' opinions. A few studies have been conducted, mainly using focus groups, in patients with joint hypermobility syndrome (a condition overlapping with hEDS and now belonging to the hypermobility spectrum disorders) [14,15]. Although one study 
established an assessment tool for JHS patients (the Bristol Impact of Hypermobility), the correspondence with the needs of hEDS patients has not been assessed [15].

Such an evaluation could be conducted using the Delphi method. This method aims to get a consensus on experts' opinions on a given topic [16,17]. Usually, researchers send a questionnaire to a group of respondents and then, based on the results, create a new survey for the same respondents [17]. The Delphi technique is commonly used in a wide variety of fields including the health care sciences [18-20].

The aim of this study was to determine from questionnaires submitted to hEDS patients what symptoms they perceive as having the greatest impact on their well-being and, according to them, what symptoms should be assessed.

\section{Material and methods}

\section{Participants}

Respondents were recruited through a French national EDS patient's association (SED1+) by means of an email distribution to association's members. All participants were Frenchspeaking. Respondents were excluded, based on the answers to the first questionnaire, if they were not diagnosed by a medical doctor or if they did not specify the EDS subtype. Only unique and complete answers were collected. All other patients diagnosed with EDS were included for the first round of analysis.

All participants gave their online informed consent as part of the first questionnaire. The protocol was approved by the Ethics Committee of the University of Lille. 


\section{Study design}

This is a questionnaire study based on the Delphi technique with online questionnaires conducted with the LimeSurvey software [21].

The Delphi technique aims to get a consensus on experts' opinions on a given topic $[16,17]$. For our purpose, the experts are patients with an EDS, and the topic is the determination of the main symptoms that influence their health and which should therefore be assessed.

The study was organized into three rounds, each of which involved a new questionnaire. The first round included the online informed consent, the collection of the e-mail address for further rounds, questions about demographical data, inclusion and exclusion criteria and the main question about symptoms. This round is conducted in order to determine the symptom categories which will be used in the following rounds. After analysis and determination of the symptom categories, the second round consists of having the patients rank the categories obtained during the first round. At the end of this second round, global concordance is calculated in order to see if there is a consensus. If the concordance rate is too low, the least important categories (based on the ranking by participants) are eliminated and a new ordering is proposed with the remaining categories.

\section{First round: establishment of categories}

Questions about age and sex were asked on a first questionnaire as well as the following questions (in French) about diagnosis and the main question about symptoms: "Have you been diagnosed with EDS by a medical doctor?"; "Did the diagnosis specify a specific form of EDS, if so which one?"; "How long have you been diagnosed?"; "What are the main symptoms that influence your health and which we should assess?". Respondents also gave their online informed consent and their email address in order to be contacted for the second round. 
After exclusions of respondents who did not fulfil the inclusion and exclusion criteria, the symptom categories from responses at the main question were extracted. For each respondent all symptoms described were noted down. Symptoms were regrouped or separated according to their frequency of appearance in the responses. For example, "headache" was often cited separately from "pain" and these were separated into two distinct categories. The symptom categories were discussed between the authors. They were updated as the responses were collected, and after establishing a first list of categories, the number of responses corresponding to each category were counted. A ranking of symptom categories was established according to their frequency of appearance. The ten most frequent categories were kept for a second round in order to limit the number of possible answers. The demographical and diagnosis-related data were analysed with descriptive statistics in order to define the population.

\section{Second round: first ranking}

Once the symptom categories were established, they were sent by email with a request to rank them by importance. Only hEDS participants from the first round were contacted in the second round in order to get a homogeneous population. The other EDS subtypes were excluded.

The ten categories extracted from the first round were presented with a description of what each category contained. For this presentation, categories are listed in an alphabetical order (to avoid response bias) and no information about number of occurrences for each category was given. Participants were asked to rank the categories from the most important to the least important to assess. The question (in French) was, "What are the main symptoms that influence your health and which we should assess? Rank the symptoms from the most important to assess in your opinion to the least important to assess". An additional box allowed participants to make comments. 
For each response, a value was given from 1 (least important) to 10 (most important) for each category according to ranking. The sum and the mean of these values for each category were calculated in order to get the ranking. Concordance was evaluated with R [22] with a Kendall coefficient of concordance test. A consensus was obtained if $\mathrm{W} \geq 0.70$ and $\mathrm{p}<0.05$. If data didn't match conditions for the consensus, the lowest ranked categories were eliminated and a third round was started similar to the second one with only the remaining categories.

\section{Third round: second ranking}

The third round is launched only if there is no consensus at the end of the second round. It is similar to the second round after elimination of the lowest ranked categories. At the sending of the third round, a return on the results of the second round was made by giving the average ranking of each category so that the participants were aware of the answers of the whole panel. It was decided not to continue to a fourth round.

\section{Results}

\section{First round: establishment of categories}

A total of 146 responses was collected. Among these, 28 were excluded for the reasons cited above (see figure 1 for more details on exclusions). Of the remaining 118 respondents, 107 (90.7\%) were diagnosed hEDS, 8 (6.8\%) were diagnosed classical EDS (cEDS), 2 (1.7\%) were diagnosed vascular EDS (vEDS) and $1(0.8 \%)$ was diagnosed kyphoscoliotic EDS (kEDS). Demographical data are presented in table 1 . The population has a majority of women $(94.1 \%)$, more than half of whom are between 40 and 60 years old $(56.8 \%)$ and the majority had been diagnosed for 1 to 5 years $(54.2 \%)$.

With the first analysis of open question responses, 16 categories were established. The following changes were made before the second analysis in order to be as consistent as possible 
with the responses. As described in the Methods section, "headache" was often cited separately from "pain" and this is why headache and pain are classified as two different categories. It was also decided to integrate musculoskeletal pain in the pain category in order to leave only "mechanical" disorders in the musculoskeletal disorders category. In the same way, respiratory disorders were frequently described by the respondents and were dissociated from the cardiological disorders, which in responses relate more to the autonomic disorders. Walking, proprioception and balance disorders have been gathered together as fatigue and sleep disorders.

In order to get a reduced number of categories for the second round, we had to select categories of symptoms according to the frequency of occurrence of these symptoms. Ten categories are identified and described with symptoms reported in table 2. A last group has all the symptoms not included in any category and was not used for the second round. The percentage of citation for each category is presented in figure 2 .

\section{Second round: first ranking}

The second round consisted in ranking the categories extracted from the first round according to their order of importance. Only hEDS patients were contacted for this round. Eighty-seven complete responses were collected over the $107 \mathrm{hEDS}$ contacted (81\%) (figure 1).

A value of 10 was assigned to the category ranked as most important, and a value of 1 to the category ranked as least important. The ranking of "the main symptoms that influence your health and which we should assess" is presented in figure 3. The categories in order of mean ranking were; pain $(8.7 \pm 1.7)$, fatigue and sleep disorders $(7.7 \pm 2.3)$, musculoskeletal disorders $(6.9 \pm 2.4)$, walking/proprioception/balance $(5.5 \pm 2.1)$, gastro-intestinal disorders $(5.1 \pm 2.4)$, headaches $(4.8 \pm 3.0)$, cognitive disorders $(4.7 \pm 2.4)$, autonomic disorders $(4.5 \pm 2.3)$, respiratory disorders $(4.0 \pm 2.5)$ and psychological disorders $(3.1 \pm 2.4)$. 
Using a Kendall's coefficient of concordance on the data, we found $\mathrm{W}=0.33$ with $\mathrm{p}<0.001$ ( $\mathrm{s}=205504, \chi^{2}=258, \mathrm{df}=9, \mathrm{n}=87, \mathrm{~N}=10$ ). This value is under the cut-off value of 0.7 that would show consensus.

Regarding the mean values for each category and the Kendall's coefficient of concordance, it was decided to keep the four highest ranked categories. Keeping a fifth category (gastrointestinal) was discussed among the authors. It was decided not to keep it for the third round because of the closeness of its mean to the three following categories and the poor value of concordance for this second round.

\section{Third round: second ranking}

As the second round did not lead to a consensus, a third round was conducted keeping only the four categories considered most important. Categories were ranked according to their order of importance. The same respondents as in the second round were contacted (107 hEDS patients). Eighty-seven complete responses were collected (81\%) (figure 1).

A value of 4 was assigned to the category ranked as most important, and a value of 1 to the category ranked as least important. The ranking of "the main symptoms that influence your health and which we should assess" is presented in figure 4. The categories in order of mean ranking were; pain (3.5 \pm 0.8$)$, fatigue and sleep disorders (2.8 \pm 1.0$)$, musculoskeletal disorders $(2.2 \pm 0.9)$ and walking/proprioception/balance $(1.5 \pm 0.8)$.

Using a Kendall's coefficient of concordance on the data, we found $\mathrm{W}=0.43$ with $\mathrm{p}<0.001$ ( $\mathrm{s}=16417, \chi^{2}=113, \mathrm{df}=3, \mathrm{n}=87, \mathrm{~N}=4$ ). This value is under the cut-off value of 0.7 that would show consensus.

\section{Discussion}


The objective of this study was to determine, from a questionnaire submitted to hEDS patients, what symptoms they perceive as having the most impact on their well-being and, according to them, what symptoms have to be assessed. To our knowledge this is the first study focusing on the importance of symptoms for hEDS patients using the Delphi technique in order to reach a consensus.

The responses obtained in the first round are in agreement with the high phenotypic variability of the hEDS $[2-5,23]$. A large majority cited pain $(88.1 \%)$ as well as fatigue and sleep disorders $(72.0 \%)$ spontaneously, making them relatively common characteristics. This was repeated in the following rounds and these two categories, along with the musculoskeletal disorders, stood out in the second round from the other categories. However, consensus about the most important symptoms to assess according to hEDS patients was not reached, despite a third round conducted with only four categories.

The demographic characteristics found in this study are in accordance with other EDS data as there is a predominance of symptoms in females and as hEDS is the most common EDS subtype [2]. The population in the current study is predominantly between 40 and 60 years old, with a time since diagnosis for more than a half between 1 and 5 years. This is consistent with a late diagnosis which is commonly reported in EDS studies [24,25].

The choice to conduct the second and third rounds only on hEDS patients was made in order to have as homogeneous a population as possible. Respondents indicating that they did not have a particular form of diagnosed EDS were excluded from this study at the beginning.

Musculoskeletal disorders were cited spontaneously by only $39.8 \%$ of respondents in the first round as a symptom to be assessed despite the high proportion of hEDS which is characterized by hypermobility. Since musculoskeletal disorders are very frequently reported in hEDS patients $[3,5,6]$, it is surprising that less than one out of two patients spontaneously cited it as a 
symptom to be evaluated. One possible explanation is that musculoskeletal pain has been classified in the pain category and is therefore not accounted for in the musculoskeletal disorders category.

The respiratory disorders category was cited by $22 \%$ of respondents, just after gastro-intestinal disorders (25\%) which is a documented symptom category in hEDS [26]. Respiratory symptoms have been relatively poorly studied in hEDS [27], and are often classified with cardiovascular symptoms or as cardiorespiratory symptoms in hEDS studies $[3,4,23]$. In view of the large number of symptoms in this category spontaneously cited by patients, we preferred to keep this category separate from cardiac symptoms and to associate heart related symptoms (mainly tachycardia, hypotension, and frequency or rhythm disorders) with autonomic symptoms. The indication of respiratory symptoms by about $1 / 5$ of hEDS patients should encourage future studies on this part of the disease.

As underlined for the first round, these results show that there is a great variability in the opinions of hEDS patients about the most important symptom to assess. This is also shown by the concordance rate, which was only $33 \%$ in the second round. This suggests that the symptom assessment need to be individualized for each patient. This could take the form, as used here, of a ranking (in order of importance), by the patient, of the different categories of symptoms. This would allow evaluations to be focused on what matters most to the patient without leaving out what practitioners deem necessary. Such an approach would require a new study to evaluate this kind of tool. However, we can note a tendency to recognize three main categories that stand out. These categories are in order "pain", "fatigue and sleep disorders" and "musculoskeletal disorders". The "pain" category appears in the first 3 categories for $81.6 \%$ of respondents, fatigue and sleep disorders for $64.4 \%$ and musculoskeletal disorders for $47.1 \%$. It is interesting to note that these results, based on patients' opinions, correspond to the main factors, pain and fatigue, influencing quality of life found in other studies, based on measurement scales, in adult 
and young patients with EDS or JHS [3,28-31]. Then follow a group of six categories with a close average ranking score between 4 and 5.5/10, and finally the category psychological disorders with an average of $3.1 / 10$. It is also interesting to note that although the literature has shown frequent and significant associations with various psychological disorders [32,33], this category is classified as the least important to assess. We can see that $65.5 \%$ of respondents classified psychological disorders in the last 3 categories to be evaluated. This could raise the question of the acceptance of this symptom category for patients with hEDS. One possible explanation is that patients are not necessarily able to differentiate a psychological disorder from its associated symptoms. Furthermore, the aetiology of many of the symptoms may be physical, psychological or mixed, which is reflected in the high prevalence of subjective health complaints in EDS [34,35], and does not facilitate the identification of the signs of certain psychological disorders. As no particular conclusions could be drawn from the ranking of gastrointestinal disorders, headaches, cognitive disorders or autonomic disorders, these categories will not be discussed.

Symptoms related to walking, proprioception and balance were grouped together because of their clinical proximity and to limit the number of categories to be classified by respondents. It is obvious that this classification of symptoms into categories is purely semantic and that in daily life most of these categories interact with each other, but for more objectivity it was necessary to separate them in order to better target the needs of the patients. Other categories could have been added to the ten categories but the number was intentionally restricted in order to limit the extent of the possibilities during the second round ranking. The maintenance of only four categories allows a fair balance between too great a reduction which would have facilitated consensus but whose significance would have been altered, or too large a choice which would not have led to consensus. But, once again, the ranking was not unanimous since the rate of 
concordance of the answers only reached $43 \%$. It is interesting to note that the average ranking between these 4 categories is the same as in the second round.

A study by Palmer et al. (2017) led to the development of an assessment questionnaire for Joint Hypermobility Syndrome (JHS) patients: the Bristol Impact of Hypermobility (BIOH) [15]. It is interesting to note that the items of this questionnaire, established through focus groups and working groups with JHS patients, focus on pain, fatigue and the consequences of hypermobility. These three elements correspond to the most important categories to be assessed according to the hEDS patients in our study. Although the methods used in the two studies are different, the results are concordant and therefore seem to support the use of the BIOH with hEDS patients.

One limitation of this study is the use of patient-reported diagnosis. The first questionnaire was constructed to limit selection bias as much as possible. The possibility of answers indicating that the respondent had not been diagnosed by a doctor, or not to know the subtype of EDS, as well as the possibility of completing the questionnaire even in case of exclusion should promote transparency. However, the true proportion of respondents who have EDS was not measured. The recruitment that was conducted through a single national patient association may also be considered a limitation. The Delphi technique used here to collect an overall opinion does not provide the same level of detail as other more qualitative techniques such as focus groups. Thus the reasons why some symptoms are considered more important than others could not be explored. It does however allow a more quantitative approach to the patient's experience and should be considered as complementary to qualitative studies.

In conclusion, symptoms of pain, fatigue and sleep disorders and musculoskeletal disorders seem to be the most important to assess in patients with hEDS, however, there was not 
consensus on this ranking. This data should be taken into account in the establishment of a standardized screening tool for research and for the direction of care.

\section{Acknowledgements:}

The authors would like to thank the patients who have agreed to participate in this study as well as the patients association SED1+ who participated in the good progress of the protocol and Ms. Elise Dangtran-Ciccarelli and Mr. Thomas Gillard for their precious help in the translation of this work.

\section{Disclosure statement:}

The authors report no conflicts of interest.

\section{Funding:}

This research did not receive any specific grant from funding agencies in the public, commercial, or not-for-profit sectors.

\section{Data Availability Statement:}

The data that support the findings of this study are available from the corresponding author, $\mathrm{AH}$, upon reasonable request. 


\section{References}

[1] Malfait F, Francomano C, Byers P, et al. The 2017 international classification of the EhlersDanlos syndromes. Am J Med Genet C Semin Med Genet. 2017;175:8-26.

[2] Tinkle B, Castori M, Berglund B, et al. Hypermobile Ehlers-Danlos syndrome (a.k.a. EhlersDanlos syndrome Type III and Ehlers-Danlos syndrome hypermobility type): Clinical description and natural history. Am J Med Genet C Semin Med Genet. 2017;175:48-69.

[3] Castori M, Camerota F, Celletti C, et al. Natural history and manifestations of the hypermobility type Ehlers-Danlos syndrome: A pilot study on 21 patients. Am J Med Genet A. 2010;152A:556564.

[4] De Wandele I, Rombaut L, Malfait F, et al. Clinical heterogeneity in patients with the hypermobility type of Ehlers-Danlos Syndrome. Res Dev Disabil. 2013;34:873-881.

[5] Murray B, Yashar BM, Uhlmann WR, et al. Ehlers-Danlos syndrome, hypermobility type: A characterization of the patients' lived experience. Am J Med Genet A. 2013;161:2981-2988.

[6] Rombaut L, Malfait F, Cools A, et al. Musculoskeletal complaints, physical activity and healthrelated quality of life among patients with the Ehlers-Danlos syndrome hypermobility type. Disabil Rehabil. 2010;32:1339-1345.

[7] Rombaut L, Malfait F, De Paepe A, et al. Impairment and impact of pain in female patients with Ehlers-Danlos syndrome: A comparative study with fibromyalgia and rheumatoid arthritis. Arthritis Rheum. 2011;63:1979-1987.

[8] Tran ST, Jagpal A, Koven ML, et al. Symptom complaints and impact on functioning in youth with hypermobile Ehlers-Danlos syndrome. J Child Health Care. 2019;136749351986717.

[9] Corrado B, Ciardi G. Hypermobile Ehlers-Danlos syndrome and rehabilitation: taking stock of evidence based medicine: a systematic review of the literature. J Phys Ther Sci. 2018;30:843847.

[10] Bennett SE, Walsh N, Moss $\mathrm{T}$, et al. Understanding the psychosocial impact of joint hypermobility syndrome and Ehlers-Danlos syndrome hypermobility type: a qualitative interview study. Disabil Rehabil. 2019;1-10.

[11] Bennett SE, Walsh N, Moss T, et al. The lived experience of Joint Hypermobility and EhlersDanlos Syndromes: a systematic review and thematic synthesis. Phys Ther Rev. 2019;24:12-28.

[12] Berglund B, Nordström G, Lützén K. Living a restricted life with Ehlers-Danlos Syndrome (EDS). Int J Nurs Stud. 2000;37:111-118.

[13] Bovet C, Carlson M, Taylor M. Quality of life, unmet needs, and iatrogenic injuries in rehabilitation of patients with Ehlers-Danlos Syndrome hypermobility type/Joint Hypermobility Syndrome. Am J Med Genet A. 2016;170:2044-2051.

[14] Terry RH, Palmer ST, Rimes KA, et al. Living with joint hypermobility syndrome: patient experiences of diagnosis, referral and self-care. Fam Pract. 2015;32:354-358.

[15] Palmer S, Cramp F, Lewis R, et al. Development and initial validation of the Bristol Impact of Hypermobility questionnaire. Physiotherapy. 2017;103:186-192. 
[16] Dalkey N, Helmer O. An Experimental Application of the DELPHI Method to the Use of Experts. Manag Sci. 1963;9:458-467.

[17] Linstone HA, Turoff M, editors. The Delphi method: techniques and applications. Reading, Mass: Addison-Wesley Pub. Co., Advanced Book Program; 1975.

[18] Diamond IR, Grant RC, Feldman BM, et al. Defining consensus: A systematic review recommends methodologic criteria for reporting of Delphi studies. J Clin Epidemiol. 2014;67:401-409.

[19] Lange T, Schmitt J, Kopkow C, et al. What Do Patients Expect From Total Knee Arthroplasty? A Delphi Consensus Study on Patient Treatment Goals. J Arthroplasty. 2017;32:2093-2099.e1.

[20] van den Driessen Mareeuw FA, Coppus AMW, Delnoij DMJ, et al. Capturing the complexity of healthcare for people with Down syndrome in quality indicators - a Delphi study involving healthcare professionals and patient organisations. BMC Health Serv Res. 2020;20.

[21] LimeSurvey Project Team, Carsten Schmitz. LimeSurvey: An Open Source survey tool [Internet]. Hamburg, Germany: LimeSurvey Project; 2012. Available from: http://www.limesurvey.org.

[22] R Core Team. R : A Language and environment for statistical computing [Internet]. R Foundation for Statistical Computing. Vienna, Austria; 2017. Available from: http://www.R-project.org/.

[23] Rombaut L, Malfait F, De Wandele I, et al. Medication, Surgery, and Physiotherapy Among Patients With the Hypermobility Type of Ehlers-Danlos Syndrome. Arch Phys Med Rehabil. 2011;92:1106-1112.

[24] McGillis L, Mittal N, Santa Mina D, et al. Utilization of the 2017 diagnostic criteria for hEDS by the Toronto GoodHope Ehlers-Danlos syndrome clinic: A retrospective review. Am J Med Genet A. 2020;182:484-492.

[25] Bénistan K, Martinez V. Pain in hypermobile Ehlers-Danlos syndrome: New insights using new criteria. Am J Med Genet A. 2019;179:1226-1234.

[26] Fikree A, Chelimsky G, Collins H, et al. Gastrointestinal involvement in the Ehlers-Danlos syndromes. Am J Med Genet C Semin Med Genet. 2017;175:181-187.

[27] Reychler G, Liistro G, Piérard GE, et al. Inspiratory muscle strength training improves lung function in patients with the hypermobile Ehlers-Danlos syndrome: A randomized controlled trial. Am J Med Genet A. 2019;179:356-364.

[28] Hakim A, De Wandele I, O'Callaghan C, et al. Chronic fatigue in Ehlers-Danlos syndromeHypermobile type. Am J Med Genet C Semin Med Genet. 2017;175:175-180.

[29] Chopra P, Tinkle B, Hamonet C, et al. Pain management in the Ehlers-Danlos syndromes. Am J Med Genet C Semin Med Genet. 2017;175:212-219.

[30] Mu W, Muriello M, Clemens JL, et al. Factors affecting quality of life in children and adolescents with hypermobile Ehlers-Danlos syndrome/hypermobility spectrum disorders. Am J Med Genet A. 2019;179:561-569.

[31] Pacey V, Tofts L, Adams RD, et al. Quality of life prediction in children with joint hypermobility syndrome: Quality of life in youth hypermobility. J Paediatr Child Health. 2015;51:689-695. 
[32] Baeza-Velasco C, Bourdon C, Montalescot L, et al. Low- and high-anxious hypermobile EhlersDanlos syndrome patients: comparison of psychosocial and health variables. Rheumatol Int. 2018;38:871-878.

[33] Bulbena A, Baeza-Velasco C, Bulbena-Cabré A, et al. Psychiatric and psychological aspects in the Ehlers-Danlos syndromes. Am J Med Genet C Semin Med Genet. 2017;175:237-245.

[34] Hope L, Juul-Kristensen B, Løvaas H, et al. Subjective health complaints and illness perception amongst adults with Joint Hypermobility Syndrome/Ehlers-Danlos SyndromeHypermobilityType - a cross-sectional study. Disabil Rehabil. 2019;41:333-340.

[35] Maeland S, Assmus J, Berglund B. Subjective health complaints in individuals with EhlersDanlos syndrome: A questionnaire study. Int J Nurs Stud. 2011;48:720-724. 
Fig. 1

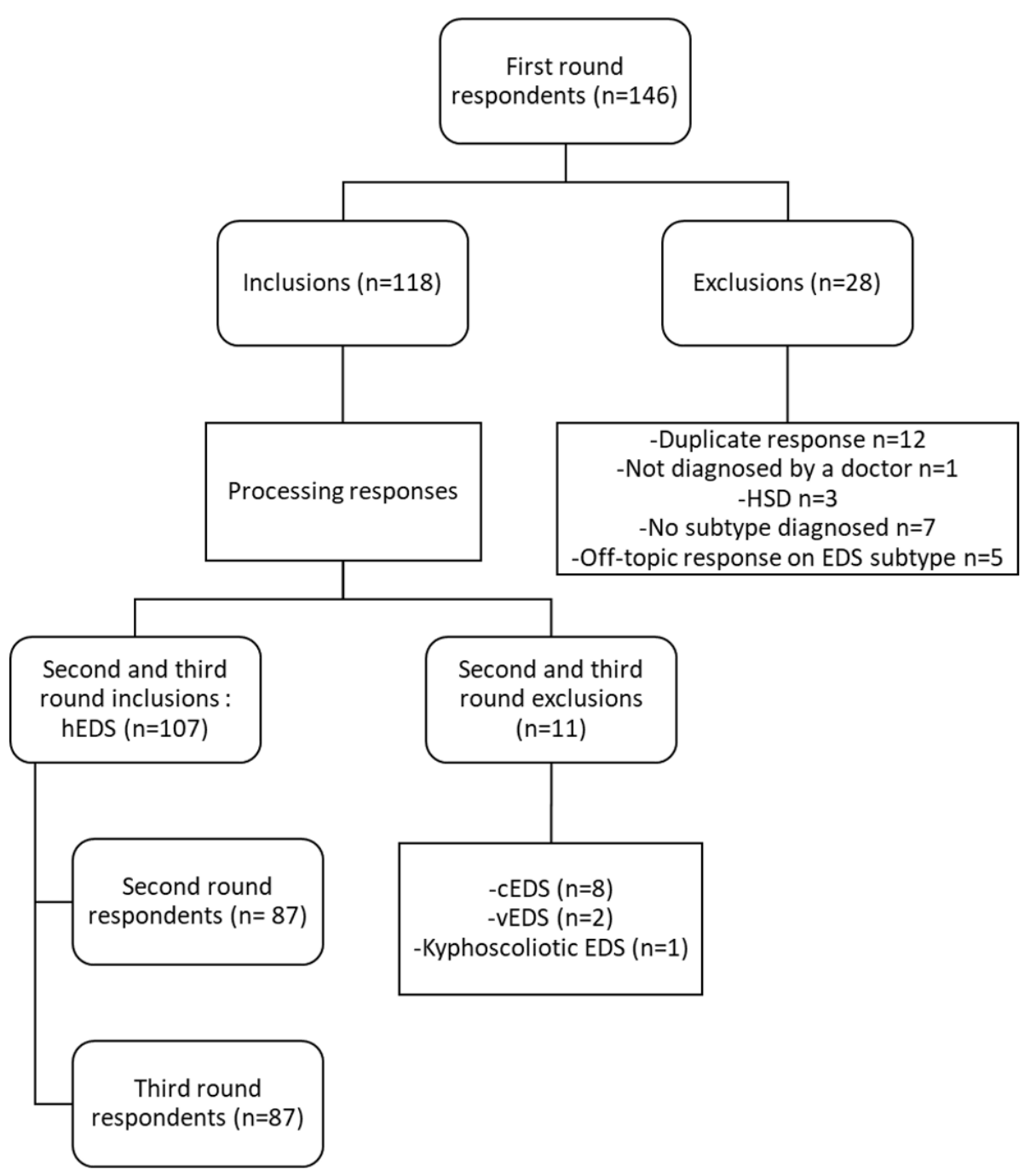

Figure 1: Inclusion and exclusion flowchart. 
Fig. 2

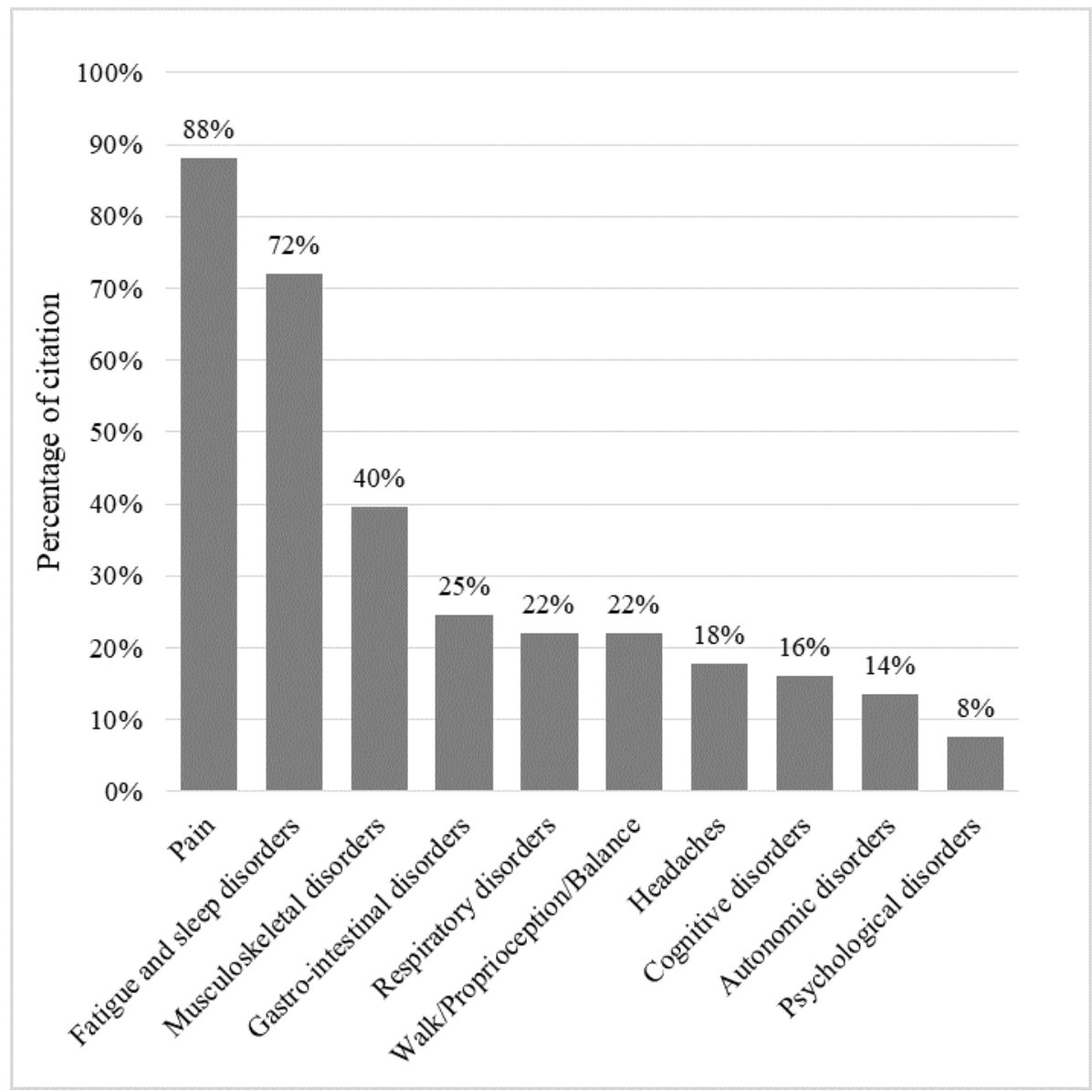

Figure 2 Caption: First round percentage of citation per category for all included respondents (n=118). Reponses to the question "What are the main symptoms that influence your health and which we should assess?". 
Fig. 3



Figure 3 Caption: Second round ranking distribution $(n=87)$.

Responses to the question "What are the main symptoms that influence your health and which we should assess? Rank the symptoms from the most important to assess in your opinion [...] to the least important to assess [...]". A value of 10 was assigned to the category ranked as most important, and a value of 1 to the category ranked as least important. Boxplots represent from bottom to top: minimum, first quartile, median, third quartile and maximum. Black diamonds and values represent the mean. 
Fig. 4

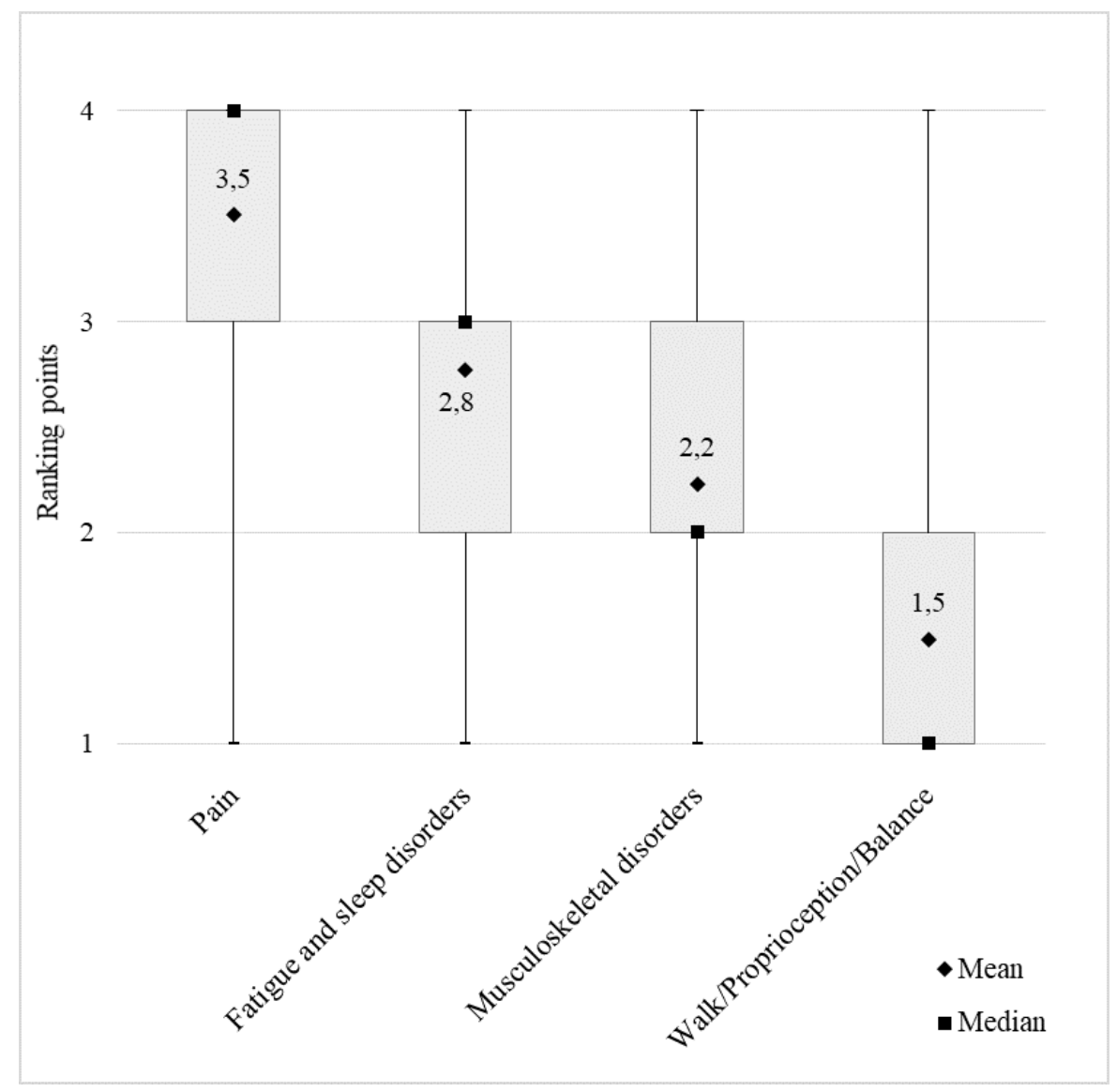

Figure 4 Caption: Third round ranking distribution $(n=87)$.

Responses to the question "What are the main symptoms that influence your health and which we should assess? Rank the symptoms from the most important to assess in your opinion [...] to the least important to assess [...] '. A value of 4 was assigned to the category ranked as most important, and a value of 1 to the category ranked as least important. Boxplots represent from bottom to top: minimum, first quartile, median, third quartile and maximum. As the median may be equal to the first or third quartile, it is represented by black squares. Black diamonds and values represent the mean. 
Table 1 : First round demographical data

\begin{tabular}{|c|c|c|c|c|c|c|}
\hline & & $\begin{array}{c}\text { Global } \\
n=118\end{array}$ & $\begin{array}{l}\text { hEDS } \\
\mathrm{n}=107\end{array}$ & $\begin{array}{c}\text { cEDS } \\
n=8\end{array}$ & $\begin{array}{c}\text { vEDS } \\
n=2\end{array}$ & $\begin{array}{c}\mathbf{k E D S} \\
\mathrm{n}=1\end{array}$ \\
\hline \multirow{2}{*}{ Gender } & Men & $\begin{array}{c}7 \\
(5.9 \%)\end{array}$ & $\begin{array}{c}6 \\
(5.6 \%)\end{array}$ & $\begin{array}{c}1 \\
(12.5 \%)\end{array}$ & $\begin{array}{c}0 \\
(0 \%)\end{array}$ & $\begin{array}{c}0 \\
(0 \%)\end{array}$ \\
\hline & Women & $\begin{array}{c}111 \\
(94.1 \%)\end{array}$ & $\begin{array}{c}101 \\
(94.4 \%)\end{array}$ & $\begin{array}{c}7 \\
(87.5 \%)\end{array}$ & $\begin{array}{c}2 \\
(100 \%)\end{array}$ & $\begin{array}{c}1 \\
(100 \%)\end{array}$ \\
\hline \multirow{4}{*}{$\begin{array}{c}\text { Age } \\
\text { (years) }\end{array}$} & $<20$ & $\begin{array}{c}10 \\
(8.5 \%)\end{array}$ & $\begin{array}{c}9 \\
(8.4 \%)\end{array}$ & $\begin{array}{c}0 \\
(0 \%)\end{array}$ & $\begin{array}{c}0 \\
(0 \%)\end{array}$ & $\begin{array}{c}1 \\
(100 \%)\end{array}$ \\
\hline & 20 to 40 & $\begin{array}{c}29 \\
(24.6 \%)\end{array}$ & $\begin{array}{c}27 \\
(25.2 \%)\end{array}$ & $\begin{array}{c}1 \\
(12.5 \%)\end{array}$ & $\begin{array}{c}1 \\
(50.0 \%)\end{array}$ & $\begin{array}{c}0 \\
(0 \%)\end{array}$ \\
\hline & 40 to 60 & $\begin{array}{c}67 \\
(56.8 \%)\end{array}$ & $\begin{array}{c}61 \\
(57.0 \%)\end{array}$ & $\begin{array}{c}6 \\
(75.0 \%)\end{array}$ & $\begin{array}{c}0 \\
(0 \%)\end{array}$ & $\begin{array}{c}0 \\
(0 \%)\end{array}$ \\
\hline & $>60$ & $\begin{array}{c}12 \\
(10.2 \%)\end{array}$ & $\begin{array}{c}10 \\
(9.3 \%)\end{array}$ & $\begin{array}{c}1 \\
(12.5 \%)\end{array}$ & $\begin{array}{c}1 \\
(50.0 \%)\end{array}$ & $\begin{array}{c}0 \\
(0 \%)\end{array}$ \\
\hline \multirow{6}{*}{$\begin{array}{c}\text { Diagnosed } \\
\text { since } \\
\text { (years) }\end{array}$} & $<1$ & $\begin{array}{c}17 \\
(14.4 \%)\end{array}$ & $\begin{array}{c}16 \\
(15.0 \%)\end{array}$ & $\begin{array}{c}1 \\
(12.5 \%)\end{array}$ & $\begin{array}{c}0 \\
(0 \%)\end{array}$ & $\begin{array}{c}0 \\
(0 \%)\end{array}$ \\
\hline & 1 to 5 & $\begin{array}{c}64 \\
(54.2 \%) \\
\end{array}$ & $\begin{array}{c}56 \\
(52.3 \%) \\
\end{array}$ & $\begin{array}{c}6 \\
(75.0 \%) \\
\end{array}$ & $\begin{array}{c}1 \\
(50 \%)\end{array}$ & $\begin{array}{c}1 \\
(100 \%)\end{array}$ \\
\hline & 5 to 10 & $\begin{array}{c}28 \\
(23.7 \%)\end{array}$ & $\begin{array}{c}26 \\
(24.3 \%)\end{array}$ & $\begin{array}{c}1 \\
(12.5 \%)\end{array}$ & $\begin{array}{c}1 \\
(50 \%)\end{array}$ & $\begin{array}{c}0 \\
(0 \%)\end{array}$ \\
\hline & 10 to 15 & $\begin{array}{c}7 \\
(5.9 \%)\end{array}$ & $\begin{array}{c}7 \\
(6.5 \%) \\
\end{array}$ & $\begin{array}{c}0 \\
(0 \%)\end{array}$ & $\begin{array}{c}0 \\
(0 \%)\end{array}$ & $\begin{array}{c}0 \\
(0 \%)\end{array}$ \\
\hline & 15 to 20 & $\begin{array}{c}2 \\
(1.7 \%)\end{array}$ & $\begin{array}{c}2 \\
(1.9 \%)\end{array}$ & $\begin{array}{c}0 \\
(0 \%)\end{array}$ & $\begin{array}{c}0 \\
(0 \%)\end{array}$ & $\begin{array}{c}0 \\
(0 \%)\end{array}$ \\
\hline & $>20$ & $\begin{array}{c}0 \\
(0 \%)\end{array}$ & $\begin{array}{c}0 \\
(0 \%)\end{array}$ & $\begin{array}{c}0 \\
(0 \%)\end{array}$ & $\begin{array}{c}0 \\
(0 \%)\end{array}$ & $\begin{array}{c}0 \\
(0 \%)\end{array}$ \\
\hline
\end{tabular}

Demographical data for all included respondents and for each subtype of EDS with number (percentage).

hEDS, hypermobile EDS; cEDS, classical EDS; vEDS, vascular EDS, kEDS, kyphoscoliosis $E D S$. 
Table 2: Categories description

\begin{tabular}{|c|c|c|}
\hline Categories & & Content \\
\hline $\begin{array}{l}\text { Autonomic } \\
\text { disorders }\end{array}$ & \multicolumn{2}{|c|}{$\begin{array}{l}\text { Dizziness, postural orthostatic tachycardia syndrome, faints, hypotension, dysautonomia, } \\
\text { thermoregulation disorders and heart rate or rhythm disorders. }\end{array}$} \\
\hline $\begin{array}{l}\text { Cognitive } \\
\text { disorders }\end{array}$ & \multicolumn{2}{|c|}{ Attention, memory or concentration disorders. } \\
\hline $\begin{array}{l}\text { Fatigue and } \\
\text { sleep disorders }\end{array}$ & \multicolumn{2}{|c|}{ Fatigue, fatigability, asthenia, exhaustion, insomnia and poor sleep quality. } \\
\hline $\begin{array}{l}\text { Gastro-intestinal } \\
\text { disorders }\end{array}$ & \multicolumn{2}{|c|}{$\begin{array}{l}\text { Digestive or transit disorders, food intolerance, gastro-intestinal hypersensitivity, mast } \\
\text { cell activation syndrome, nausea, gastroesophageal reflux, overweight and dysphagia. }\end{array}$} \\
\hline Headaches & \multicolumn{2}{|l|}{ Cephalalgia, headaches and migraine. } \\
\hline $\begin{array}{l}\text { Musculoskeletal } \\
\text { disorders }\end{array}$ & \multicolumn{2}{|c|}{$\begin{array}{l}\text { Joint disorders (arthrosis, sprain, luxation, inflammation, discopathy, dysplasia and } \\
\text { instability) muscles disorders (contractures, weakness, dystonia and fragility), tendonitis, } \\
\text { hypermobility, stiffness and bone fragility. }\end{array}$} \\
\hline Pain & \multicolumn{2}{|c|}{ All pain except headache (muscular, articular, abdominal, neuropathic and neuralgia). } \\
\hline $\begin{array}{l}\text { Psychological } \\
\text { disorders }\end{array}$ & \multicolumn{2}{|c|}{$\begin{array}{l}\text { Stress, depression, cyclothymia, autism spectrum disorder, behavioral disorders, low } \\
\text { self-esteem and sensory-processing sensitivity. }\end{array}$} \\
\hline $\begin{array}{l}\text { Respiratory } \\
\text { disorders }\end{array}$ & \multicolumn{2}{|c|}{$\begin{array}{l}\text { Dyspnea, pulmonary disorders, bronchiectasis, pneumonia, respiratory failure, asthma, } \\
\text { pulmonary embolism and sleep apnea. }\end{array}$} \\
\hline $\begin{array}{l}\text { Walking, } \\
\text { Proprioception } \\
\text { and Balance } \\
\text { disorders }\end{array}$ & \multicolumn{2}{|c|}{$\begin{array}{l}\text { Proprioception disorders, balance disorders, falls, walking disorders, postural instability } \\
\text { and inability to walk. }\end{array}$} \\
\hline \multirow{13}{*}{$\begin{array}{l}\text { Unclassified } \\
\text { symptoms }\end{array}$} & Eye disorders $(n=7)$ & Vision, diplopia, blepharoptosis and glaucoma. \\
\hline & Otolaryngological disorders $(\mathrm{n}=5)$ & $\begin{array}{l}\text { Tongue hypotonia, swallowing disorders, sinusitis } \\
\text { and voice disorders }\end{array}$ \\
\hline & Urogynecological disorders $(n=5)$ & $\begin{array}{l}\text { Stress incontinence, gynecological disorders, } \\
\text { urinary infection, menstrual disorders and urinary } \\
\text { retention. }\end{array}$ \\
\hline & Skin disorders $(n=5)$ & $\begin{array}{l}\text { Capillary fragility, easy bruising, mottled skin and } \\
\text { cicatrization. }\end{array}$ \\
\hline & Circulatory disorders $(\mathrm{n}=4)$ & Varicose veins and edema \\
\hline & Tremors $(n=4)$ & - \\
\hline & Paresthesia $(n=3)$ & - \\
\hline & Hearing disorders $(n=3)$ & Deafness and hyperacusis \\
\hline & $\begin{array}{l}\text { Temporomandibular disorders } \\
(\mathrm{n}=3)\end{array}$ & $\begin{array}{l}\text { Blockage and temporomandibular joint-pain- } \\
\text { dysfunction syndrome. }\end{array}$ \\
\hline & Drug intolerance $(n=2)$ & - \\
\hline & Limb numbness $(\mathrm{n}=2)$ & - \\
\hline & Difficulty with positioning $(\mathrm{n}=2)$ & - \\
\hline & Others (all $n=1)$ & $\begin{array}{l}\text { Uncontrolled movements, vestibular disorders, } \\
\text { prolapse, hernia, anesthesia, eczema, dysgraphia, } \\
\text { adrenal insufficiency, complicated positioning, } \\
\text { staying up all day, exercise intolerance and } \\
\text { difficulty in exercise recovery. }\end{array}$ \\
\hline
\end{tabular}

